\title{
Applied multimodal diagnostics in a case of presenile dementia
}

\author{
Sonja Schönecker ${ }^{1 *} \mathbb{D}$, Matthias Brendel ${ }^{2}$, Marion Huber ${ }^{1}$, Christian Vollmar ${ }^{1}$, Hans-Juergen Huppertz ${ }^{3}$, \\ Stefan Teipel ${ }^{4,5}$, Nobuyuki Okamura ${ }^{6}$, Johannes Levin ${ }^{1,7}$, Axel Rominger ${ }^{2}$ and Adrian Danek
}

\begin{abstract}
Background: Alzheimer's disease (AD) is the most common cause of dementia in the elderly. The possibility of disease-modifying strategies has evoked a need for early and accurate diagnosis. To improve the accuracy of the clinical diagnosis of AD, biomarkers like cerebrospinal fluid (CSF) and neuroimaging techniques like magnetic resonance imaging (MRI) and positron emission tomography (PET) have been incorporated into the diagnostic guidelines of AD.
\end{abstract}

Case presentation: In this case report we outline in reference to one of our patients with presenile dementia the current approaches to the diagnosis of AD. The patient was a 59-year old woman presenting with progressive memory decline. CSF-A $\beta_{42}$ was normal while P-tau was slightly increased. FDG-PET indicated a pattern typical for $A D$, amyloid-PET showed an extensive global amyloid load, and tau-PET depicted a pronounced hippocampal tracer accumulation. The MRI scan was rated as normal at routine diagnostics, however quantitative volumetric analysis revealed significant atrophy especially of the parietal lobe. The combination of biomarkers and neuroimaging techniques was therefore suggestive of an underlying $A D$ pathology.

Conclusions: To enable early and accurate diagnosis of $A D$ and thereby also patient recruitment for anti-tau or anti- $\beta$-amyloid therapeutic trials, a combination of biomarkers and neuroimaging techniques seems useful.

Keywords: Case report, Alzheimer's disease, Biomarkers, CSF, MRI, FDG-PET, tau-PET, Amyloid-PET

\section{Background}

Alzheimer's disease (AD) is the most common cause of dementia and is estimated to affect 106.8 million people worldwide by the year 2050 [1]. It is clinically characterized by progressive memory and language impairment, functional and behavioural disturbances and visuospatial deficits [2]. A definite diagnosis of AD still relies on postmortem histopathological detection of intracellular neurofibrillary tangles and extracellular amyloid plaques [3]. It is widely acknowledged that histopathological changes start years before clinical manifestation of the disease [4]. As first disease modifying therapies are approaching early and accurate diagnosis of $\mathrm{AD}$ becomes increasingly important [5]. Therefore the National Institute on Aging and the Alzheimer's Association have revised the criteria for the diagnosis of AD [6]. To assess the probability of an

\footnotetext{
* Correspondence: sonja.schoenecker@med.uni-muenchen.de

${ }^{1}$ Department of Neurology, Ludwig-Maximilians University, Munich, Germany

Full list of author information is available at the end of the article
}

underlying $\mathrm{AD}$ pathology biomarkers of the disease and neuroimaging techniques have been incorporated into the diagnostic guidelines of $\mathrm{AD}$. Here we present an exemplary case of presenile dementia based on which we discuss the approaches to the diagnosis of AD.

\section{Case presentation}

A 59 year old retired attorney, with 18 years of education presented with a three year history of progressive memory decline. For about one year she hadn't been able to do the shopping or the cooking. No behavioural changes, language impairment, severe fluctuations of attention and alertness, recurrent visual hallucinations or history of repetitive brain trauma were reported. Family history was positive, her mother as well as an uncle had developed late-onset dementia.

The Mini-Mental-State Examination which had been performed three years ago because of subjective memory impairment had been rated as normal. For neuropsychological testing we applied the CERAD plus battery 
additionally including Trail Making Test A and B as well as verbal fluency tests. The scores of almost all domains of the CERAD plus battery were at least -1.37 standard deviations below the age- and education-adjusted norm values. She scored 24 out of 30 points in the MiniMental-State Examination. Naming (Boston-Naming-test) was intact whereas phonemic verbal fluency was slightly (11 words in $1 \mathrm{~min}$ ) and semantic fluency (9 words in $1 \mathrm{~min}$ ) was highly reduced. Memory was highly impaired. She displayed intrusions and showed a reduced performance of word list recall and recognition. Constructional practice was impaired as well. Results of the Trail-Making Test showed reduced visual attention as well as reduced speed of processing. Cognitive flexibility measured by Trail-Making-Test B was also poor.

At first presentation the neurological examination was normal. In particular no manifest or latent paresis and no sensory deficit could be detected. Deep tendon reflexes were mildly hypoactive without any pathological reflexes. Cranial nerves were also intact. There was no evidence of extrapyramidal features.

Laboratory tests for metabolic causes of dementia, for example for vitamin $B_{12}$, thyroid, liver and renal function, thiamine level and folate were within the normal range. P-tau (66 pg/ml, N $<61 \mathrm{pg} / \mathrm{ml}$ ) in cerebrospinal fluid (CSF) was only slightly increased, whereas total Tau $(293 \mathrm{pg} / \mathrm{ml}$, $\mathrm{N}<500 \mathrm{pg} / \mathrm{ml})$ and $\mathrm{A} \beta_{42}(1171 \mathrm{pg} / \mathrm{ml}, \mathrm{N}>500 \mathrm{pg} / \mathrm{ml})$ were normal. All other CSF parameters were within the normal range.

The MRI scan which had been performed three years ago as well as the MRI scan at first presentation were interpreted as normal at visual inspection. Especially no sign of global or regional atrophy could be detected. However, atlas-based volumetric MRI analysis [7, 8] showed a significant reduction especially of temporal and parietal lobe volumes. Z-scores for the hippocampal and parietal volumes compared to healthy controls were -2.9 and -4.2 respectively (Fig. 1).

Moreover, a quantitative analysis based on voxel-wise z-score analysis of patient grey matter segments and grey matter segments from an age and sex-matched control sample after bias correction and spatial normalization in a common standard space following an established method [9] showed a slight asymmetry with more pronounced atrophy of rightsided parietotemporal cortical areas (voxel based grey matter reduction $\mathrm{z}>-1.96$ ) (Fig. 2). It has to be noted that for the quantitative analysis, data of the comparison group came from another MRI scanner than the scan of the patient. Acquisition parameters were harmonized between scanners to accommodate possible scanner effects.

Fluorodeoxyglucose-PET (FDG-PET) showed an asymmetric reduction of brain glucose metabolism of parietal and temporal cortical areas with a more pronounced

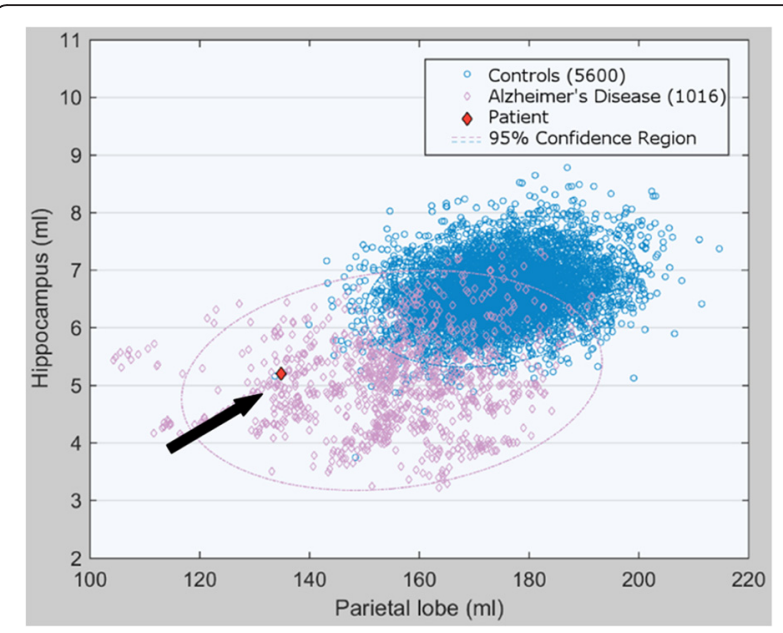

Fig. 1 Volumetric MRI analysis of our patient's (dark arrow) hippocampus and parietal lobe compared to AD patients and age-matched healthy controls after intracranial-volume correction. Z-scores of hippocampal and parietal lobe volume compared to healthy controls were -2.9 and -4.2 respectively. Our patient's datapoint lay within the $95 \%$ confidence region of Alzheimer's disease and outside the $95 \%$ confidence region of

healthy controls and was therefore automatically assigned to the Alzheimer's disease group

reduction of glucose metabolism in the right hemisphere. In addition glucose metabolism of the posterior cingulate cortex was significantly reduced (Fig. 2).

The patient underwent a florbetaben-PET (FBB-PET) scan which showed extensive FBB retention that was greater in parietotemporal, frontal and posterior cingulate/precuneus cortex and less pronounced in the occipital cortex. Basal ganglia were also slightly affected (Fig. 3).

The tau-PET scan with THK-5351 on the other hand showed high tracer retention in both hippocampi as well as moderately increased tracer retention in parietotemporal cortical areas. There was no elevated tracer retention in other cortical areas (Fig. 3).

\section{Conclusions}

As our patient presented with a three year history of cognitive decline that interfered with activities of daily living and scored low in almost all domains of the CERAD plus battery a clinical diagnosis of $\mathrm{AD}$ was made [6]. Because of the presenile age at onset and the positive family history a monogenic form of AD might be possible. Genetic testing could have excluded conditions mimicking sporadic AD-like dementia. Our patient however refused genetic testing. Sensitivity and specificity of the clinical diagnosis of $\mathrm{AD}$ compared to post-mortem histopathological diagnosis ranges from 70.9 to $87.3 \%$ and from 44.3 to $70.8 \%$ respectively [10]. The combination of biomarkers and neuroimaging techniques was suggestive of an underlying $\mathrm{AD}$ pathology. In absence of a neuropathological 


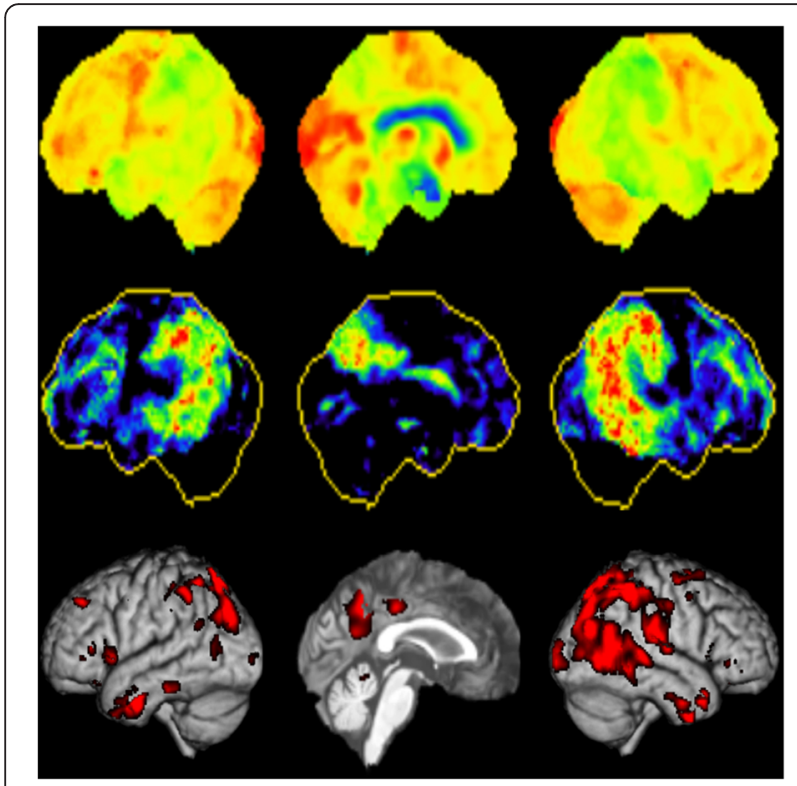

Fig. 2 Positron emission tomography of the brain with F-18-labeled fluorodeoxyglucose (FDG-PET) and three-dimensional surface representation of brain regions with grey matter reduction of our 59-year-old AD patient compared to 18 healthy controls. Top: regional uptake of radiolabelled glucose; the left lateral, left medial and right lateral views of the brain are presented. Middle: regional metabolic reduction compared to age-matched healthy controls according to the methodology of Minoshima et al. [53]. There is an asymmetric metabolic reduction parietotemporal and in posterior cingulate cortex with a more pronounced reduction of glucose metabolism in the right hemisphere. Bottom: color-coded brain matter reduction. Z-values of grey matter reduction are projected on T1-weighted, averaged brain surface of healthy control subjects

confirmation of $\mathrm{AD}$ pathology, a definite diagnosis of $\mathrm{AD}$, however, was not possible. The most important alternative diagnosis in a case of presenile dementia are dementia with Lewy bodies (DLB), frontotemporal dementia with memory impairment (FTD) and chronic traumatic encephalopathy (CTE). As our patient had no pronounced variation in attention and alertness, reported no recurrent visual hallucinations and displayed no features of parkinsonism the core features of DLB were not fulfilled [11]. Furthermore no progressive deterioration of personality or social comportment was reported and there was no evidence of progressive language impairment. Therefore there was no clinical evidence for behavioural variant frontotemporal dementia [12] or primary progressive aphasia [13]. As there was no history of recurrent impacts to the head or body, CTE seemed unlikely as well [14]. Table 1 summarizes biomarker and neuroimaging findings in autopsy confirmed cases of DLB, FTD and CTE. [References in Table 1: [15-30]]. In the following the current diagnostic approaches used in the diagnosis of $\mathrm{AD}$ are illustrated with reference to our 59-year old patient.

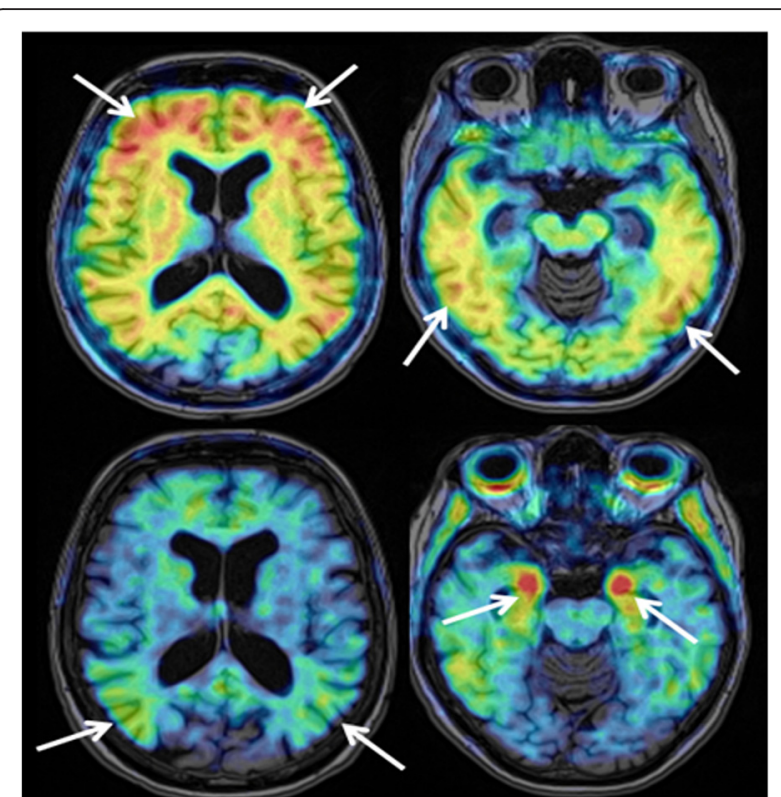

Fig. $3 A \beta$ and tau imaging with FBB (top) and THK-5351 (bottom) of our 59 year old patient with Alzheimer's disease. FBB and THK-5351 binding patterns demonstrate the different distributions of $A \beta$ and tau deposits in the brain of our Alzheimer's disease patient. FBB-PET scan revealed a massive global amyloid load with a pronounced FBB retention in parietotemporal, frontal and posterior cingulate/precuneal cortices. In contrast THK-5351 retention was markedly elevated in the hippocampus, whereas onlya slightly increased THK-5351 retention was observed in parietotemporal cortical areas

Neuropsychological testing is commonly used as an aid in diagnosing $\mathrm{AD}$. In our patient the scores of almost all domains of the CERAD plus battery were well below average. Memory was most severely affected. As the earliest pathological changes in AD occur in medial temporal lobe structures [31] episodic memory is usually the first cognitive ability to decline, typically followed, like in our case by additional deficits in language and semantic knowledge, executive functions, working memory, attention and visuospatial abilities [32].

Results of laboratory testing for example for vitamin $B_{12}$, thyroid function, thiamine level and folate, were within the normal range. Laboratory testing should be performed in every AD patient to rule out metabolic causes of dementia.

CSF did not suggest malignancy, neuroinflammation or infection. P-tau that reflects the intensity of neuronal degeneration was slightly increased. Interestingly, although amyloid-PET revealed an extensive global amyloid load, CSF-A $\beta_{42}$ on the other hand was normal. It has been shown that amyloid load at autopsy of AD patients is inversely correlated to CSF-A $\beta_{42}$ whereas tau load is positively correlated to CSF P-tau and total tau [33]. Yet although CSF and amyloid-PET measurements of $\mathrm{A} \beta_{42}$ are consistent in the majority of patients a dissociation 
Table 1 Summary of biomarker and neuroimaging findings in autopsy confirmed DLB, FTD and CTE cases

\begin{tabular}{|c|c|c|c|}
\hline & Population & CSF biomarker/Ligand & Major findings \\
\hline \multicolumn{4}{|l|}{ CSF } \\
\hline \multirow[t]{2}{*}{ Clark et al.(15] } & \multirow[t]{2}{*}{60 AD, 10 FTD, 3 DLB } & \multirow[t]{2}{*}{ total Tau, Aß42 } & higher total tau in AD compared to FTD and DLB \\
\hline & & & $A \beta 42$ reduced in $A D$ compared to FTD but not compared to DLB \\
\hline \multirow[t]{2}{*}{ Slaets et al. [16] } & \multirow{2}{*}{$\begin{array}{l}30 \mathrm{AD} \text {, } \\
13 \mathrm{DLB} \text { with SP, } \\
5 \mathrm{DLB} \text { without SP } \\
30 \mathrm{AD} \text {, } \\
9 \text { DLB with NFT, } 9 \text { DLB } \\
\text { without NFT }\end{array}$} & P-Tau, total Tau, Aß42 & $\begin{array}{l}A \beta 42 \text { reduced in } A D \text { and } D L B \text { with } S P \text { compared to } D L B \text { without } S P \\
\text { no difference in } A \beta 42 \text { levels of } A D \text { and } D L B \text { with } S P \text { patients }\end{array}$ \\
\hline & & P-Tau, total Tau, Aß42 & $\begin{array}{l}\text { P-Tau higher in AD compared to DLB with and without NFT } \\
\text { no difference in P-Tau levels of DLB with and without NFT } \\
\text { no difference of total Tau between the DLB subgroups and AD }\end{array}$ \\
\hline Koopmann et al. [17] & 95 AD, 18 DLB, 10 FTD & P-Tau, total Tau, Aß42 & $\begin{array}{l}\text { P-Tau cut-off for differentiating AD from FTD } 35.3 \mathrm{pg} / \mathrm{ml} \text {, } \\
\text { from DLB } 52.8 \mathrm{pg} / \mathrm{ml} \\
\text { total Tau level: } A D>D L B>\text { FTD } \\
\text { A } 42 \text { level: } A D<D L B=F T D\end{array}$ \\
\hline Bian et al. [18] & AD 19, FTD 30 & total Tau, A $\beta 42$ & total Tau and tau/Aß42 ratio lower in FTD than in AD \\
\hline Toledo et al. [19] & 71 AD, 29 FTD & P-Tau, total Tau, Aß42 & $\begin{array}{l}\text { high sensitivity and specificity of combined CSF biomarkers } \\
\text { in classifying AD against FTD } \\
\text { P-Tau and total Tau higher in AD compared to FTD } \\
\text { A } 442 \text { lower in AD compared to FTD }\end{array}$ \\
\hline \multicolumn{4}{|l|}{ MRI } \\
\hline Vemuri et al. [20] & $48 \mathrm{AD}, 47 \mathrm{FTD}, 20 \mathrm{DLB}$ & & $\begin{array}{l}\text { atrophy pattern in AD: temporoparietal association cortices } \\
\text { and medial temporal lobe } \\
\text { FTD: frontal and temporal lobes } \\
\text { DLB: bilateral amygdalae, dorsal midbrain, inferior temporal lobe }\end{array}$ \\
\hline Rabinovici et al. [21] & $11 \mathrm{AD}, 18 \mathrm{FTD}$ & & $\begin{array}{l}\text { atrophy in AD: posterior temporoparietal and occipital atrophy } \\
\text { atrophy in FTD: medial prefrontal and medial temporal } \\
\text { cortex, insula, hippocampus, amygdala }\end{array}$ \\
\hline Burton et al. [22] & $11 \mathrm{AD}, 23 \mathrm{DLB}$ & & $\begin{array}{l}\text { pronounced medial temporal lobe atrophy in AD compared to } \\
\text { DLB patients }\end{array}$ \\
\hline Kantarci et al. [23] & $2 A D, 3 D L B$ & & more pronounced hippocampal atrophy in AD compared to DLB \\
\hline Mckee et al. [24] & $1 \mathrm{CTE}$ & & $\begin{array}{l}\text { generalized cortical atrophy, enlargement of ventricles, cavum } \\
\text { septum pellucidum }\end{array}$ \\
\hline \multicolumn{4}{|l|}{ FDG-PET } \\
\hline Minoshima et al. [25] & $10 \mathrm{AD}, 4 \mathrm{DLB}$ & & $\begin{array}{l}\mathrm{AD} \text { and DLB: hypometabolism in posterior cingulate, } \\
\text { parietotemporal and frontal association cortices } \\
\text { additional occipital hypometabolism in DLB }\end{array}$ \\
\hline Albin et al. [26] & 3 AD-DLB, 3 DLB & & $\begin{array}{l}\text { compared to AD additional hypometabolism in occipital } \\
\text { association and primary visual cortex }\end{array}$ \\
\hline Kantarci et al. [23] & $2 \mathrm{AD}, 3 \mathrm{DLB}$ & & low occipital FDG-uptake in 1 AD patient and all DLB patients \\
\hline Foster et al. [27] & 31 AD, 14 FTD & & $\begin{array}{l}\text { AD: temporoparietal and posterior cingulate hypometablism } \\
\text { FTD: frontal, anterior cingulate and anterior temporal hypometabolism }\end{array}$ \\
\hline \multicolumn{4}{|l|}{ Amyloid-PET } \\
\hline \multirow[t]{2}{*}{ Kantarci et al. [23] } & $2 \mathrm{AD}, 3 \mathrm{DLB}$ & PiB & $\begin{array}{l}\text { high global cortical PiB retention in one AD patient, low } \\
\text { global cortical PiB in the other }\end{array}$ \\
\hline & & & $\begin{array}{l}2 \text { DLB patients with borderline PiB retention, } 1 \text { DLB } \\
\text { patient with high PiB retention }\end{array}$ \\
\hline Bacskai et al. [28] & $1 \mathrm{DLB}$ & PiB & $\begin{array}{l}\text { tracer uptake in posterior cingulate, precuneus, posterior parietal, } \\
\text { middle and inferior temporal, insular, lateral and orbital frontal cortices }\end{array}$ \\
\hline Rabinovici et al. [29] & $3 \mathrm{AD}, 7 \mathrm{FTD}$ & $\mathrm{PiB}$ & $\begin{array}{l}\text { higher PiB retention in AD compared to FTD } \\
\text { better classification accuracy of PiB-PET compared to FDG-PET }\end{array}$ \\
\hline \multicolumn{4}{|l|}{ Tau-PET } \\
\hline Ghetti et al. [30] & 1 FTD & T807 & $\begin{array}{l}\text { elevated tracer uptake in anterior, temporal and parietal cortex as } \\
\text { well as basal ganglia }\end{array}$ \\
\hline
\end{tabular}


between $A \beta_{42}$ measurements is not uncommon [34]. Especially the combination of CSF biomarkers may increase diagnostic certainty of AD pathology. Yet, as CSF biomarkers do not change during the clinical phase of $\mathrm{AD}$, they cannot be used as markers of disease progression [35]. In comparison to AD patients, DLB and FTD patients present significantly lower P-tau and total tau levels [17]. There is however some overlap in CSF P-tau and total tau between AD, DLB and FTD patients. $A \beta_{42}$ is generally decreased in DLB. Most studies could not define valuable CSF $A \beta_{42}$ cut-off scores for differentiation of DLB from AD [36]. CSF $A \beta_{42}$ levels of FTD patients on the other hand are significantly higher compared to $\mathrm{AD}$ patients [18]. The combination of CSF P-tau, total tau and $\mathrm{A} \beta_{42}$ has shown high diagnostic sensitivity and specificity in distinguishing AD from DLB and FTD patients. In CTE one would expect normal CSF $A \beta_{42}$ levels and an elevated P-tau/total tau ratio [14]. Large biomarker studies on autopsy confirmed CTE cases however are lacking. AS CSF P-tau was only slightly increased while CSF total tau and $A \beta_{42}$ were within the normal range, CSF analysis was not suggestive of an underlying AD pathology in our case.

The MRI scan was interpreted as normal at routine diagnostics, especially no sign of normal-pressure hydrocephalus, cerebrovascular disease, tumours or regional/ global atrophy could be detected. Volumetric MRI analysis however revealed significant atrophy of the parietal and temporal lobe, especially of the hippocampus, and may therefore be useful to obtain rater- independent and objective results $[7,8]$. Comparison of atrophy patterns can differentiate $\mathrm{AD}$ patients with a high sensitivity and specificity from healthy controls and other dementia syndromes like DLB and FTD [20]. In DLB significant gray matter loss is detectable in bilateral amygdalae, the middle temporal lobe as well as the dorsal ponto-mesencephalic junction area [20]. In FTD patients atrophy is normally restricted to the frontal and temporal lobes, with relative sparing of the parietal and occipital lobes. MRI may also be useful to detect neuropathological changes observed in CTE like whole brain atrophy or cavum septum pellucidum with occasional fenestration [24]. In our case volumetric MRI analysis showed a typical AD atrophy pattern with pronounced atrophy of the parietal and temporal lobe, especially the hippocampus, and therefore supported the diagnosis of $\mathrm{AD}$. In Alzheimer's disease patients, especially hippocampal atrophy (Fig. 1) seems to be highly correlated with episodic memory impairment [37].

In the FDG-PET scan (Fig. 2) the typical AD pattern consisting of a reduction of cerebral glucose metabolism in precuneus, posterior cingulate and parietotemporal association cortices [38] could be detected. In comparison, DLB patients show an additional significant metabolic reduction in the occipital cortex, particularly the primary visual cortex, which distinguishes DLB with a high sensitivity and specificity from AD patients [25]. FTD on the other hand causes hypometabolism in the frontal lobes, the anterior temporal cortex and anterior cingulate cortex [27]. FDG-PET studies that evaluated glucose metabolism in subjects with repetitive brain trauma have shown inconsistent findings $[39,40]$. In summary, FDGPET clearly supported $\mathrm{AD}$ as the most probable diagnosis in our case. Like structural MRI, FDG-PET represents a marker of neuronal injury. Retrospective investigations showed a sensitivity of $84 \%$ and a specificity of $74 \%$ for FDG-PET in predicting post-mortem AD pathology at autopsy [41]. FDG-PET thereby outperformed the initial clinical evaluation. Furthermore, FDG-PET seems to be a suitable predictor of conversion to $\mathrm{AD}$ in patients with mild cognitive impairment [42].

Amyloid- and tau-Pet represent new diagnostic tools. To present a definite diagnosis of $\mathrm{AD}$ relies on postmortem histopathology. Yet these new imaging techniques permit non-invasive visualization and quantification of the two histological hallmarks of the disease.

Amyloid-PET showed a characteristic increase of tracer uptake in cortical regions known to have a high amount of amyloid burden in $\mathrm{AD}$, i.e. frontal, parietal and lateral temporal cortex (Fig. 3). DLB patients can show a similar pattern yet with lower amount of $A \beta$ ligand binding compared with AD patients [43]. FTD patients on the other hand display low cortical tracer retention such that amyloid PET has shown high accuracy in discriminating $\mathrm{AD}$ from FTD $[44,45]$. Variable degrees of diffuse $\beta$-amyloid can be detected in about $47 \%$ of autopsy confirmed CTE cases [46]. Amyloid-PET may therefore differentiate between CTE and AD by identifying different amyloiddeposition patterns. Further studies are needed to determine the topography of $\beta$-amyloid depositions in CTE. Showing a high amount of tracer uptake in parietotemporal, frontal and posterior cingulate/precuneus cortex, FBB-PET was suggestive for AD in our case. Recent phase III studies in which the in-vivo uptake of 18-F-labelled amyloid tracers was compared to post-mortem amyloid load showed a sensitivity and specificity of 88 to $92 \%$, and 88 to $100 \%$ respectively for the detection of amyloid deposits in $\mathrm{AD}$ patients [47-49]. As amyloid deposition probably represents a very early event in the course of the disease that occurs years before onset of dementia symptoms, amyloid-PET may allow early and even presymptomatic diagnosis [4].

Increased tau-tracer retention could be detected in parietotemporal cortical areas, especially in the hippocampus (Fig. 3). In contrast to amyloid-PET the sensitivity and specificity of tau-PET imaging have yet to be determined. Post-mortem studies have shown that the amount of tau deposition is highly related to the severity of dementia [50]. In addition to aiding in the early and differential diagnosis of Alzheimer's disease tau-PET may therefore 
serve as a marker of disease progression. Recently, first experiences with tau-PET in DLB were reported [51]. Tau deposition is elevated in some cases of DLB, especially in the inferior temporal region. Tau-PET scans may be positive in some variants of FTD. A first case report of a P301L MAPT mutation carrier showing elevated tau tracer uptake in frontal, anterior temporal and parietal cortex as well as in basal ganglia has been published [30]. Hitherto a single case report of a patient with a clinical diagnosis of CTE who underwent tau-PET imaging has been published [52]. Increased tracer uptake could be detected in globus pallidus, putamen, hippocampus and substantia nigra. Because of increased tracer retention in basal ganglia the detected distribution of tracer retention seemed more suggestive of progressive supranuclear palsy. However the patient did not manifest the typical clinical symptoms of progressive supranuclear palsy. In summary tau-PET also supported a diagnosis of AD in our case.

Overall, although CSF $A \beta_{42}$ was normal, the combination of biomarker and neuroimaging findings in this case was still suggestive of $\mathrm{AD}$ pathology. Table 2 rates the biomarker and neuroimaging findings of our case with respect to possible differential diagnosis.

As some of the illustrated diagnostic approaches provided converging evidence, e.g. CSF P-tau, MRI, FDGPET and Tau-PET each indicated an AD typical neuronal degeneration and thereby provided somewhat redundant information, the necessity for a diagnostic algorithm becomes obvious. A sequential diagnostic process where widely available diagnostic tools like neuropsychological testing to establish the diagnosis of a dementia syndrome and laboratory testing to exclude metabolic causes of dementia are performed in a first step may be useful. Such a baseline testing could help to select patients that profit from further diagnostic work-up. In a second step CSF examination and structural MRI may be rational, on the one hand to further exclude potentially treatable causes of dementia like neuroinflammation or normal pressure hydrocephalus and on the other hand to obtain evidence for an $\mathrm{AD}$-related pathological process and $\mathrm{AD}$ typical

Table 2 Rating of biomarker and neuroimaging findings of our case with respect to possible differential diagnosis

\begin{tabular}{lllll}
\hline Biomarker/neuroimaging findings & $\mathrm{AD}$ & $\mathrm{FTD}$ & $\mathrm{DLB}$ & $\mathrm{CTE}$ \\
\hline CSF P-tau & + & - & - & - \\
CSF A 342 & - & $\mathrm{O}$ & - & 0 \\
MRI - clinical routine & $\mathrm{O}$ & $\mathrm{O}$ & $\mathrm{O}$ & 0 \\
MRI - voxel-based & ++ & - & + & - \\
FDG-PET & ++ & - & $\mathrm{O}$ & - \\
amyloid-PET & ++ & - & + & + \\
tau-PET & ++ & $\mathrm{O}$ & $\mathrm{O}$ & 0 \\
\hline
\end{tabular}

++ highly increases probability, + increases probability, O probability unchanged, - decreases probability neuronal degeneration. In patients presenting with an atypical clinical course or atypically early age of onset the more expensive nuclear medicine diagnostic techniques FDG-, amyloid- and tau-PET might be useful to differentiate between $\mathrm{AD}$ and important differential diagnoses like pseudo-dementia or frontotemporal dementia. They may also serve as markers of disease progression and prognostic markers. Especially tau and amyloid imaging may furthermore be useful for patient recruitment and serve as a surrogate marker for monitoring the efficacy of future anti-tau or anti-amyloid strategies.

\section{Abbreviations}

$A D$, Alzheimer's disease; CSF, cerebrospinal fluid; CTE, chronic traumatic encephalopathy; DLB, dementia with lewy bodies; FBB, florbetaben; FDG,

fluorodeoxyglucose; FTD, frontotemporal dementia; MRI, magnetic resonance imaging; PET, positron emission tomography

Funding

No funding was obtained

Availability of data and materials

All data are presented in the manuscript. There are no additional data.

Authors' contributions

SS coordinated and drafted the manuscript and figures; MB, CV, HJH, ST, $\mathrm{NO}, \mathrm{AR}$ were involved in imaging acquisition and analyses; $\mathrm{MH}$ was involved in patient care; $M B, M H, C V, H J H, S T, A R, J L, N O, A D$ critically revised the manuscript. All authors read and approved the final manuscript.

\section{Competing interests}

The authors declare that they have no competing interests.

\section{Consent for publication}

Written informed consent for publication of this Case Report and any accompanying images was obtained from the patient's next of kin, i.e. her husband. A copy of the written consent is available for review to the Editor of this journal.

Ethics approval and consent to participate Not applicable.

\section{Author details}

'Department of Neurology, Ludwig-Maximilians University, Munich, Germany. ${ }^{2}$ Department of Nuclear Medicine, Ludwig-Maximilians University, Munich, Germany. ${ }^{3}$ Swiss Epilepsy Center, Zurich, Switzerland. ${ }^{4}$ Department of Psychosomatic Medicine, University of Rostock, Rostock, Germany. ${ }^{5}$ German Center for Neurodegenerative Diseases, Rostock, Germany. ${ }^{6}$ Department of Pharmacology, Tohoku University School of Medicine, Sendai, Japan. ${ }^{7}$ German Center for Neurodegenerative Diseases, Munich, Germany.

Received: 2 March 2016 Accepted: 26 July 2016

Published online: 09 August 2016

References

1. Brookmeyer R, Johnson E, Ziegler-Graham K, Arrighi HM. Forecasting the global burden of Alzheimer's disease. Alzheimer's \& Dementia. 2007:3(3):186-91.

2. Cummings JL. Alzheimer's Disease. The New England journal of medicine. 2004;351:56-67.

3. Jellinger KA. Neuropathology of Dementia Disorders. Journal of Alzheimer's Disease \& Parkinsonism. 2014;4:135.

4. Bateman RJ, Xiong C, Benzinger TLS, Fagan AM, Goate A, Fox NC, Marcus DS, Cairns NJ, Xie X, Blazey TM, et al. Clinical and Biomarker Changes in Dominantly Inherited Alzheimer's Disease. New England Journal of Medicine. 2012;367(9):795-804. 
5. Bergmans BA, De Strooper B. $\gamma$-secretases: from cell biology to therapeutic strategies. The Lancet Neurology. 2010;9(2):215-26.

6. McKhann GM, Knopman DS, Chertkow H, Hyman BT, Jack CR, Kawas $\mathrm{CH}$, Klunk WE, Koroshetz WJ, Manly JJ, Mayeux R. The diagnosis of dementia due to Alzheimer's disease: Recommendations from the National Institute on Aging-Alzheimer's Association workgroups on diagnostic guidelines for Alzheimer's disease. Alzheimer's \& Dementia. 2011;7(3):263-9.

7. Huppertz H-J, Kroell-Seger J, Kloeppel S, Ganz RE, Kassubek J. Intra- and interscanner variability of automated voxel-based volumetry based on a 3D probabilistic atlas of human cerebral structures. Neurolmage. 2010;49(3):2216-24.

8. Frings L, Yew B, Flanagan E, Lam BY, Hull M, Huppertz HJ, Hodges JR, Hornberger M. Longitudinal grey and white matter changes in frontotemporal dementia and Alzheimer's disease. PloS one. 2014;9(3):e90814.

9. Teipel SJ, Reuter S, Stieltjes B, Acosta-Cabronero J, Ernemann U, Fellgiebel A, Filippi M, Frisoni G, Hentschel F, Jessen F, et al. Multicenter stability of diffusion tensor imaging measures: a European clinical and physical phantom study. Psychiatry research. 2011;194(3):363-71.

10. Beach TG, Monsell SE, Phillips LE, Kukull W. Accuracy of the clinical diagnosis of Alzheimer disease at National Institute on Aging Alzheimer Disease Centers, 2005-2010. Journal of neuropathology and experimental neurology. 2012;71(4):266-73.

11. McKeith IG, Dickson DW, Lowe J, Emre M, O'Brien JT, Feldman H, Cummings J, Duda JE, Lippa C, Perry EK, et al. Diagnosis and management of dementia with Lewy bodies: third report of the DLB Consortium. Neurology. 2005;65(12):1863-72.

12. Rascovsky K, Hodges JR, Knopman D, Mendez M, Kramer JH, Neuhause J, van Swieten JC. Sensitivity of revised diagnostic criteria for the behavioural variant of frontotemporal dementia. Brain. 2011;134:2456-77.

13. Gorno-Tempini ML, Hillis AE, Weintraub S, Kertesz A, Mendez M, Cappa SF, Ogar JM, Rohrer JD, Black S, Boeve BF, et al. Classification of primary progressive aphasia and its variants. Neurology. 2011;76:1006-14.

14. Montenigro PH, Baugh CM, Daneshvar DH, Mez J, Budson AE, Au R, Katz DI, Cantu RC, Stern RA. Clinical subtypes of chronic traumatic encephalopathy: literature review and proposed research diagnostic criteria for traumatic encephalopathy syndrome. Alzheimers Res Ther. 2014;6(5):68.

15. Clark CM, Xie S, Chittams J, Ewbank D, Peskind E, Galasko D, Morris JC, McKeel DW, Farlow M, Weitlauf SL. Cerebrospinal fluid tau and $\beta$-amyloid: how well do these biomarkers reflect autopsy-confirmed dementia diagnoses? Archives of neurology. 2003;60(12):1696-702.

16. Slaets S, Le Bastard N, Theuns J, Sleegers $K$, Verstraeten A, De Leenheir E, Luyckx J, Martin J-J, Van Broeckhoven C, Engelborghs S. Amyloid pathology influences a 1 1-42 cerebrospinal fluid levels in dementia with lewy bodies. Journal of Alzheimer's Disease. 2013;35(1):137-46.

17. Koopman K, Le Bastard N, Martin JJ, Nagels G, De Deyn PP, Engelborghs S Improved discrimination of autopsy-confirmed Alzheimer's disease (AD) from non-AD dementias using CSF P-tau(181P). Neurochemistry international. 2009:55(4):214-8.

18. Bian H, Van Swieten JC, Leight S, Massimo L, Wood E, Forman M, Moore P, de Koning I, Clark CM, Rosso S, et al. CSF biomarkers in frontotemporal lobar degeneration with known pathology. Neurology. 2008;70(19 Pt 2): 1827-35.

19. Toledo JB, Brettschneider J, Grossman M, Arnold SE, Hu WT, Xie SX, Lee VM-Y, Shaw LM, Trojanowski JQ. CSF biomarkers cutoffs: the importance of coincident neuropathological diseases. Acta neuropathologica. 2012;124(1):23-35.

20. Vemuri P, Simon G, Kantarci K, Whitwell JL, Senjem ML, Przybelski SA, Gunter JL, Josephs KA, Knopman DS, Boeve BF, et al. Antemortem differential diagnosis of dementia pathology using structural MRl: Differential-STAND. Neurolmage. 2011;55(2):522-31.

21. Rabinovici G, Seeley W, Kim E, Gorno-Tempini M, Rascovsky K, Pagliaro T, Allison S, Halabi C, Kramer J, Johnson J. Distinct MRI atrophy patterns in autopsy-proven Alzheimer's disease and frontotemporal lobar degeneration. American journal of Alzheimer's disease and other dementias. 2008;22(6):474-88

22. Burton E, Barber R, Mukaetova-Ladinska E, Robson J, Perry R, Jaros E, Kalaria R, O'Brien J. Medial temporal lobe atrophy on MRI differentiates Alzheimer's disease from dementia with Lewy bodies and vascular cognitive impairment: a prospective study with pathological verification of diagnosis. Brain. 2009;132(1):195-203.
23. Kantarci K, Lowe VJ, Boeve BF, Weigand SD, Senjem ML, Przybelski SA Dickson DW, Parisi JE, Knopman DS, Smith GE. Multimodality imaging characteristics of dementia with Lewy bodies. Neurobiology of aging. 2012:33(9):2091-105.

24. Mckee AC, Cantu RC, Nowinski CJ, Hedley-Whyte ET, Gavett BE, Budson AE, Santini VE, Lee HS, Kubilus CA, Stern RA. Chronic traumatic encephalopathy in athletes: progressive tauopathy after repetitive head injury. Journal of neuropathology and experimental neurology. 2009;68(7):709-35.

25. Minoshima S, Foster NL, Sima AA, Frey KA, Albin RL, Kuhl DE. Alzheimer's disease versus dementia with Lewy bodies: cerebral metabolic distinction with autopsy confirmation. Annals of neurology. 2001;50(3):358-65.

26. Albin R, Minoshima S, D'Amato C, Frey K, Kuhl D, Sima A. Fluorodeoxyglucose positron emission tomography in diffuse Lewy body disease. Neurology. 1996;47(2):462-6.

27. Foster NL, Heidebrink JL, Clark CM, Jagust WJ, Arnold SE, Barbas NR, DeCarli CS, Turner RS, Koeppe RA, Higdon R, et al. FDG-PET improves accuracy in distinguishing frontotemporal dementia and Alzheimer's disease. Brain. 2007;130(Pt 10):2616-35.

28. Bacskai BJ, Frosch MP, Freeman SH, Raymond SB, Augustinack JC, Johnson KA, Irizarry MC, Klunk WE, Mathis CA, DeKosky ST. Molecular imaging with Pittsburgh Compound B confirmed at autopsy: a case report. Archives of neurology. 2007;64(3):431-4.

29. Rabinovici G, Rosen H, Alkalay A, Kornak J, Furst A, Agarwal N, Mormino E, O'Neil J, Janabi M, Karydas A. Amyloid vs FDG-PET in the differential diagnosis of AD and FTLD. Neurology. 2011;77(23):2034-42.

30. Ghetti B, Oblak AL, Boeve BF, Johnson KA, Dickerson BC, Goedert M. Invited review: Frontotemporal dementia caused by microtubule-associated protein tau gene (MAPT) mutations: a chameleon for neuropathology and neuroimaging. Neuropathology and applied neurobiology. 2015:41(1):24-46.

31. Braak H, Braak E. Neuropathological stageing of Alzheimer-related changes. Acta neuropathologica. 1991;82(4):239-59.

32. Salmon D. Disorders of memory in Alzheimer's disease. In: Cermak L, editor. Handbook of neuropsychology, Vol 2: Memory and its disorders. Volume 2, edn. Amsterdam: Elsevier; 2000. p. 155-95.

33. Seppala TT, Nerg O, Koivisto AM, Rummukainen J, Puli L, Zetterberg H, Pyykko OT, Helisalmi S, Alafuzoff I, Hiltunen M, et al. CSF biomarkers for Alzheimer disease correlate with cortical brain biopsy findings. Neurology. 2012;78(20):1568-75.

34. Landau SM, Lu M, Joshi AD, Pontecorvo M, Mintun MA, Trojanowski JQ Shaw LM, Jagust WJ. Comparing positron emission tomography imaging and cerebrospinal fluid measurements of $\beta$-amyloid. Annals of neurology. 2013;74(6):826-36.

35. Blennow K, Zetterberg H, Minthon L, Lannfelt L, Strid S, Annas P, Basun H, Andreasen N. Longitudinal stability of CSF biomarkers in Alzheimer's disease. Neuroscience letters. 2007;419(1):18-22.

36. Mollenhauer B, Bibl M, Wiltfang J, Steinacker P, Ciesielczyk B, Neubert K, Trenkwalder C, Otto M. Total tau protein, phosphorylated tau (181p) protein, beta-amyloid(1-42), and beta-amyloid(1-40) in cerebrospinal fluid of patients with dementia with Lewy bodies. Clinical chemistry and laboratory medicine. 2006:44(2):192-5.

37. Sexton CE, Mackay CE, Lonie JA, Bastin ME, Terrière E, O'Carroll RE, Ebmeier KP. MRI correlates of episodic memory in Alzheimer's disease, mild cognitive impairment, and healthy aging. Psychiatry Research: Neuroimaging. 2010;184(1):57-62.

38. Herholz K, Carter SF, Jones M. Positron emission tomography imaging in dementia. The British journal of radiology. 2007;80 Spec No 2:S160-167.

39. Provenzano FA, Jordan B, Tikofsky RS, Saxena C, Van Heertum RL, Ichise M. F-18 FDG PET imaging of chronic traumatic brain injury in boxers: a statistical parametric analysis. Nuclear medicine communications. 2010;31(11):952-7.

40. Peskind ER, Petrie EC, Cross DJ, Pagulayan K, McCraw K, Hoff D, Hart K, Yu CE, Raskind MA, Cook DG, et al. Cerebrocerebellar hypometabolism associated with repetitive blast exposure mild traumatic brain injury in 12 Iraq war Veterans with persistent post-concussive symptoms. Neurolmage. 2011;54 Suppl 1:S76-82.

41. Jagust W, Reed B, Mungas D, Ellis W, Decarli C. What does fluorodeoxyglucose PET imaging add to a clinical diagnosis of dementia? Neurology. 2007;69(9):871-7.

42. Landau S, Harvey D, Madison C, Reiman E, Foster N, Aisen P, Petersen R, Shaw $L$, Trojanowski J, Jack C. Comparing predictors of conversion and decline in mild cognitive impairment. Neurology. 2010;75(3):230-8. 
43. Donaghy P, Thomas AJ, O'Brien JT. Amyloid PET Imaging in Lewy body disorders. The American journal of geriatric psychiatry. 2015;23(1):23-37.

44. Rowe C, Ng S, Ackermann U, Gong S, Pike K, Savage G, Cowie T, Dickinson $K$, Maruff $P$, Darby D. Imaging $\beta$-amyloid burden in aging and dementia. Neurology. 2007;68(20):1718-25.

45. Engler H, Santillo AF, Wang SX, Lindau M, Savitcheva I, Nordberg A, Lannfelt L, Langstrom B, Kilander L. In vivo amyloid imaging with PET in frontotemporal dementia. Eur J Nucl Med Mol Imaging. 2008;35(1):100-6.

46. McKee AC, Stern RA, Nowinski CJ, Stein TD, Alvarez VE, Daneshvar DH, Lee HS, Wojtowicz SM, Hall G, Baugh CM, et al. The spectrum of disease in chronic traumatic encephalopathy. Brain. 2013;136(Pt 1):43-64.

47. Curtis C, Gamez JE, Singh U, Sadowsky CH, Villena T, Sabbagh MN, Beach TG, Duara R, Fleisher AS, Frey KA, et al. Phase 3 trial of flutemetamol labeled with radioactive fluorine 18 imaging and neuritic plaque density. JAMA neurology. 2015;72(3):287-94.

48. Sabri O, Sabbagh MN, Seibyl J, Barthel H, Akatsu H, Ouchi Y, Senda K, Murayama S, Ishii K, Takao M. Florbetaben PET imaging to detect amyloid beta plaques in Alzheimer disease: Phase 3 study. Alzheimer's \& Dementia. 2015; 11(8):964-74

49. Clark CM, Pontecorvo MJ, Beach TG, Bedell BJ, Coleman RE, Doraiswamy PM, Fleisher AS, Reiman EM, Sabbagh MN, Sadowsky CH, et al. Cerebral PET with florbetapir compared with neuropathology at autopsy for detection of neuritic amyloid- $\beta$ plaques: a prospective cohort study. The Lancet Neurology. 2012;11(8):669-78.

50. Nelson PT, Alafuzoff I, Bigio EH, Bouras C, Braak H, Cairns NJ, Castellani RJ, Crain BJ, Davies P, Del Tredici K, et al. Correlation of Alzheimer disease neuropathologic changes with cognitive status: a review of the literature. Journal of neuropathology and experimental neurology. 2012;71(5):362-81.

51. Gomperts SN, Marquie M, Locascio JJ, Bayer S, Johnson KA, Growdon JH. PET Radioligands Reveal the Basis of Dementia in Parkinson's Disease and Dementia with Lewy Bodies. Neurodegenerative Diseases. 2016;16(1-2):118-24.

52. Mitsis EM, Riggio S, Kostakoglu L, Dickstein DL, Machac J, Delman B, Goldstein M, Jennings D, D'Antonio E, Martin J, et al. Tauopathy PET and amyloid PET in the diagnosis of chronic traumatic encephalopathies: studies of a retired NFL player and of a man with FTD and a severe head injury. Translational psychiatry. 2014:4:e441.

53. Minoshima S, Frey KA, Koeppe RA, Foster NL, Kuhl DE. A diagnostic approach in Alzheimer's disease using three-dimensional stereotactic surface projections of fluorine-18-FDG PET. Journal of Nuclear Medicine. 1995;36(7):1238-48.

\section{Submit your next manuscript to BioMed Centra and we will help you at every step:}

- We accept pre-submission inquiries

- Our selector tool helps you to find the most relevant journal

- We provide round the clock customer support

- Convenient online submission

- Thorough peer review

- Inclusion in PubMed and all major indexing services

- Maximum visibility for your research

Submit your manuscript at wuw biomedcentral.com/submit

) Biomed Central 